Original research article

\title{
Molecular design, synthesis and biological characterization of novel Resveratrol derivative as potential anticancer agent targeting NF-kB
}

\author{
Zuhier Awan ${ }^{1}$, Hussam Ibrahim Kutbi ${ }^{2}$, Aftab Ahmad ${ }^{3}$, Rabbani Syed ${ }^{4}$, Faten A. S. Alsulaimany ${ }^{5}$, \\ Noor Ahmad Shaik $6,7 *$ \\ ${ }^{1}$ King Abdulaziz University, Faculty of Medicine, Department of Clinical Biochemistry, Jeddah, Kingdom of Saudi Arabia \\ ${ }^{2}$ King Abdulaziz University, Faculty of Pharmacy, Department of Pharmacy Practice, Jeddah, Kingdom of Saudi Arabia \\ ${ }^{3}$ King Abdulaziz University, Faculty of Applied Studies, Health Information Technology Department, Jedah, Kingdom of Saudi Arabia \\ ${ }^{4}$ King Saud University, College of Pharmacy, Department of Pharmaceutics, Riyadh, Kingdom of Saudi Arabia \\ ${ }^{5}$ King Abdulaziz University, Faculty of Science, Department of Biological Sciences, Jeddah, Kingdom of Saudi Arabia \\ ${ }^{6}$ King Abdulaziz University, Faculty of Medicine, Department of Genetic Medicine, Jeddah, Kingdom of Saudi Arabia \\ ${ }^{7}$ King Abdulaziz University, "Princess Al-Jawhara, Al-Brahim Center of Excellence in Research of Hereditary Disorders", Jeddah, Kingdom of Saudi Arabia
}

\begin{abstract}
Resveratrol (RESV), an anticancer nutraceutical compound, is known to show poor bioavailability inside the human body. Therefore, this study has designed multiple chemical analogs of RESV compound for improving its pharmacokinetic as well as its anti-cancer properties. Initially, the drug likeliness and ADME-toxicity properties of these new chemical analogs were tested with the help of diverse computational approaches. Then the best predicted RESV derivative is synthesized by the organic method, and its NF- $\mathrm{B}$ mediated anti-tumor activity assessed on histiocytic lymphoma U-937 cells. The new synthetic RESV analog, i.e. (E)-3-(prop-2-yn-1-yloxy)-5-(4(prop-2-yn-1-yloxy) styryl) phenol has shown a rapid, persistent and better dose-dependent ( $\mathrm{IC}_{50}$ of $\left.7.25 \mu \mathrm{M}\right)$ decrease in the viability of U937 cells than the native ( $\mathrm{IC}_{50}$ of $\left.30 \mu \mathrm{M}\right)$ RESV compound. This analog has also demonstrated its potential ability in inducing apoptosis through DNA ladder formation. At $10 \mu \mathrm{g} / \mathrm{ml}$ concentration, this chemical derivative has shown a better NF- $\kappa \mathrm{B}$ inhibition (IC ${ }_{50}$ is 2.45 ) compared to the native RESV compound ( $\mathrm{IC}_{50}$ is 1.95). Molecular docking analysis found that this analog exerts its anti- NF- $\kappa \mathrm{B}$ activity (binding energy of $-6.78 \mathrm{kcal} / \mathrm{mol}$ and $\mathrm{Ki} 10 \mu \mathrm{M}$ ) by interacting with DNA binding residues (Arg246, Lys 444 , and Gln606) of p50 chain

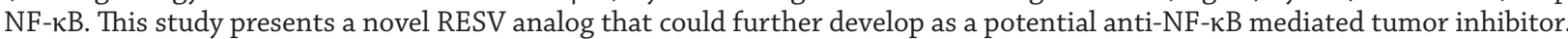

Keywords: Apoptosis; Chemical analog; Drug designing; Molecular docking; NF-кB; RESV; U-937 cell lines

\section{Highlights:}

- Resveratrol polyphenol has major anticancer properties.

- The newly synthesized RVSL-10 has high potential activity compared with parental Resveratrol compound.

- RVSL-10 inhibits the activity of NF- $\mathrm{kB}$ by binding at the transcription sites.

\section{Introduction}

The nuclear factor-kappaB (NF- $\mathrm{kB})$ belongs to the ubiquitous family of inducible transcription factors, which plays a major role in immune response, cellular proliferation, differentiation, and survival of cells (DiDonato et al., 2012). Owing to the importance of NF- $\kappa \mathrm{B}$ mediated pathways in cellular proliferation and apoptosis, several therapeutic intervention strategies have focused on blocking the binding of NF- $\kappa B$ to DNA (Kadry et al., 2018; Koch et al., 2018; Martinez et al., 2019; Zhou et al., 2014). Therefore, there has been a continuous search for synthesizing potential anti- NF- $\kappa B$ drugs, which could increase the sensitivity of cancers. In this context, natural phenolic compounds present an attractive option to effectively target constitutively active NF- $\mathrm{kB}$ in cancer cells without significant adverse effects in humans.

Many medicinal plants are known to have unique anticarcinogenic, anti-inflammatory, and growth-modulatory effects on the cancer cells (Shanmuganathan and Angayarkanni, 2018). Among them, RESV, a natural phenol compound (3,5,4'-trihydroxytrans-stilbene) with the stilbenoid chemical structure (Pangeni et al., 2014) is produced by plants against physical stress or pathogenic infections, as part of their natural defense mechanism. RESV has attracted a lot of attention as a potential phytomedicine agent against diverse types of

\footnotetext{
* Author for correspondence: Noor Ahmad Shaik, King Abdulaziz University, Faculty of Medicine, Department of Genetic Medicine, Jeddah, Saudi Arabia, Kingdom of Saudi Arabia; e-mail: nshaik@kau.edu.sa http://doi.org/10.32725/jab.2020.001

Submitted: 2019-07-04 • Accepted: 2020-01-17 • Prepublished online: 2020-02-10

J Appl Biomed 18/1: 8-17 • EISSN 1214-0287 • ISSN 1214-021X

(C) 2020 The Authors. Published by University of South Bohemia in České Budějovice, Faculty of Health and Social Sciences.

This is an open access article under the CC BY-NC-ND license.
} 
human diseases due to its involvement in multiple biological pathways like NF- $\mathrm{BB}$, Wnt, and PI3K/Akt/mTOR, etc. (Berman et al., 2017). RESV is shown to induce cell death signaling pathways and induce apoptosis in both pre-cancerous or cancer cells without affecting normal cells (Li et al., 2010; Tian and Liu, 2019; Zhang et al., 2019). However, despite well reported antitumor features of RESV, most investigations were conducted on cell culture and preclinical models, compared to very few studies on human subjects (Berman et al., 2017). But RESV could prove to be a potentially safe natural compound for treating cancer patients as compared to the traditional chemotherapy or radiotherapy induced adverse drug reactions.

The major disadvantage of using RESV in chemotherapies is that it shows poor bioavailability due to its rapid metabolism and systemic elimination properties (Sergides et al., 2016). The underlying cause for the poor bioavailability of RESV is attributable to the presence of free-OH groups and the subsequent rapid conjugation of trans-RESV to glucuronic acid and sulfates, producing glucuronides and sulfate conjugates which accumulates in plasma and urine (Almeida et al., 2009; Cottart et al., 2010; Walle et al., 2004; Yang et al., 2019). One of the effective approaches to minimize these limitations is by stabilizing RESV through chemical modification of reactive hydroxyl groups for forming a highly stable therapeutic compound (Ogas et al., 2013). Therefore, numerous studies have tried to enhance the metabolic stability and anti-proliferative activity of RESV by designing RESV derivatives, which resemble native compounds but possess modified chemical side chains on functional moieties (Ogas et al., 2013). In recent years, few investigators have successfully synthesized new RESV analogs by introducing methoxylic and hydroxylic groups on the phenolic rings of RESV. However, the synthesis of these compounds and their laboratory testing not only requires a series of chemical reactions and tedious cell line experiments but consumes lot of time. Therefore, in this study, we sought to design novel chemical analogs of RESV for increasing its stability and pharmacological effects against NF- $\kappa \mathrm{B}$, a potential molecular target of human cancers. After the initial molecular designing of library of RESV analogs, the best analog showing better pharmacokinetics and toxicity properties was chemically synthesized and biologically evaluated for its effect on cell viability, apoptosis induction ability and anti- NF- $\kappa$ B properties in a cancer cell line.

\section{Materials and methods}

\section{Library preparation}

The chemical structure of RESV (3,5,4'-Trihydroxystilbene) consists of two phenolic groups that are linked to a double styrene bond (MW $228.25 \mathrm{~g} / \mathrm{mol}$ ). In this study, we designed different RESV analog libraries by manually substituting various chemical linkers such as electron donors $\left(-\mathrm{OH},-\mathrm{CH}_{2},-\mathrm{CH}_{3}\right.$, $\left.-\mathrm{CH}_{3},-\mathrm{NH}_{2}\right)$ and electron acceptors $\left(-\mathrm{NO}_{2}\right)$ on two phenol rings $\left(R_{1}, R_{2}\right.$, and $\left.R_{3}\right)$ of RESV. Supplementary Table 1 shows the unique library of 50 chemical analogs of RESV generated by substituting different electron donor or acceptor groups.

Table 1. Physicochemical properties of RESV analogs which followed Lipinski's rule of five for a probable drug molecule

\begin{tabular}{|c|c|c|c|c|c|c|c|c|c|c|}
\hline S.No & Compound & Mi $\log P^{1}$ & TPSA $^{2}$ & $\mathrm{~N}$ atoms ${ }^{3}$ & M.W. ${ }^{4}$ & $\mathrm{nON}^{5}$ & $\mathrm{nOH} \mathrm{NH}{ }^{6}$ & Nviolations ${ }^{7}$ & Nroth $^{8}$ & $\underset{\left(\AA^{3}\right)}{\text { Volume }} e^{9}$ \\
\hline & RESV & 2.411 & 60.684 & 17 & 228.4 & 3 & 3 & 0 & 3 & 213.3 \\
\hline & RESV-7 & 7.98 & 27.70 & 23 & 304.35 & 3 & 0 & 0 & 7 & 287.54 \\
\hline & RESV-8 & 4.37 & 27.70 & 21 & 280.32 & 3 & 0 & 0 & 5 & 265.20 \\
\hline & RESV-9 & 4.16 & 27.70 & 22 & 290.32 & 3 & 0 & 0 & 5 & 270.90 \\
\hline & RESV-10 & 3.62 & 38.70 & 21 & 276.29 & 3 & $\mathbf{1}$ & $\mathbf{0}$ & 4 & 253.37 \\
\hline & RESV-11 & 3.94 & 27.70 & 23 & 300.31 & 3 & 0 & 0 & 5 & 276.60 \\
\hline & RESV-12 & 3.98 & 53.73 & 20 & 271.32 & 4 & 2 & 0 & 5 & 254.23 \\
\hline & RESV-13 & 3.36 & 79.75 & 20 & 272.30 & 5 & 4 & 0 & 5 & 248.96 \\
\hline & RESV-14 & 2.75 & 105.77 & 20 & 273.29 & 6 & 6 & 1 & 5 & 243.69 \\
\hline & RESV-21 & 2.91 & 75.71 & 18 & 243.26 & 4 & 4 & 0 & 3 & 219.18 \\
\hline & RESV-22 & 2.83 & 90.74 & 19 & 258.25 & 5 & 5 & 0 & 4 & 231.43 \\
\hline & RESV-23 & 4.81 & 51.55 & 23 & 307.35 & 4 & 1 & 0 & 8 & 287.58 \\
\hline & RESV-24 & 4.11 & 75.41 & 23 & 308.34 & 5 & 2 & 0 & 8 & 282.15 \\
\hline & RESV-25 & 3.42 & 99.26 & 23 & 309.32 & 6 & 3 & 0 & 8 & 276.72 \\
\hline & RESV-26 & 3.58 & 99.20 & 23 & 307.31 & 6 & 2 & 0 & 7 & 271.28 \\
\hline & RESV-27 & 3.75 & 99.14 & 23 & 305.29 & 6 & 1 & 0 & 6 & 265.84 \\
\hline & RESV-28 & 3.91 & 99.08 & 23 & 303.28 & 6 & 0 & 0 & 5 & 260.40 \\
\hline & RESV-29 & 4.28 & 47.93 & 20 & 272.30 & 4 & 1 & 0 & 5 & 250.96 \\
\hline & RESV-30 & 3.96 & 68.16 & 20 & 274.27 & 5 & 2 & 0 & 5 & 242.42 \\
\hline & RESV-31 & 3.64 & 88.39 & 20 & 276.24 & 6 & 3 & 0 & 5 & 233.88 \\
\hline
\end{tabular}

\footnotetext{
${ }^{1}$ MiLogP, octanol-water partition coefficient $\log \mathrm{P} ;{ }^{2} \mathrm{TPSA}$, molecular surface area; ${ }^{3} \mathrm{~N}$ atoms, number of atoms; ${ }^{4} \mathrm{M} . \mathrm{W} .$, molecular weight; ${ }^{5} \mathrm{nON}$,
} hydrogen bond donor; ${ }^{6} \mathrm{nOH} \mathrm{NH}$, hydrogen bond acceptor; ${ }^{7}$ Nviolations, number of violations; ${ }^{8}$ Nroth, number of rotatable bonds; ${ }^{9}$ Volume, molecular volume 


\section{Determination of drug likeness properties}

We have performed energy minimization for 3D coordinates of all RESV analogs using PRODRG software. In general, the natural bioactive compounds are made up of active chemical moieties similar to the already established drugs. Hence, the determination of the molecular properties of these bioactive compounds is important for discovering and developing new drugs. In this study, molinspiration computational webserver (http://www.molinspiration.com/cgi-bin/properties; Mabkhot et al., 2016) was used to determine the drug-likeliness properties of RESV analogs. The chemical structure of the query compound either in manually designed or in SMILES formats are provided to this webserver to calculate its molecular characteristics like total polar surface area (TPSA), range of atoms (natoms), molecular size (mass), number of hydrogen bond acceptors (range of $\mathrm{O}$ or $\mathrm{N}$ ), partition coefficient (miloP), range of rotatable bonds (nrotb), volume of drug distribution (molecular volume) and number of hydrogen bond donors (range of $\mathrm{OH}$ ) (Lipinski, 2004). We have considered all the above described biomolecular properties while screening for the lead RESV analogs from a pool of query compounds designed in the present investigation.

\section{Screening for ADME-Tox properties}

The biological effect of any drug and its metabolic fate in any organism depends on its ADME (absorption, digestion, metabolism, excretion) and toxicity (mutagenic, tumorigenic, irritant) properties. Hence, we evaluated ADME properties and biological properties (drug score, bioavailability, permeability, and solubility parameters) of all the potential RESV analogs using the ACD/I-Lab prediction engine (Sander et al., 2009). ACD/I-Lab browser intakes the input by drawing the structures in the I-Lab interface, pasting the structures in ACD/ ChemSketch, or accepting the structures in canonical SMILES format. This web browser surveys structural differences of chemical molecules and predicts NMR spectra and chemical shifts, physicochemical properties, and ADME toxicities of the potential drug molecule. These ADMET models can provide a quick evaluation of a few important properties like solubility, bioavailability, physicochemical determinants, oral bioavailability, distribution, acute toxicity (in mouse and rat) of any potential drug molecule.

\section{Chemical synthesis of RESV analog}

To synthesize the potential RESV analog, we followed a previously reported methodology (Banaganapalli et al., 2013). In brief, the RESV compound (100 mg; $99 \%$ pure) and $\mathrm{K}_{2} \mathrm{CO}_{3}$ (Fig. 1) mixture in dry acetone was added to propargyl bromide and heated to reflux.

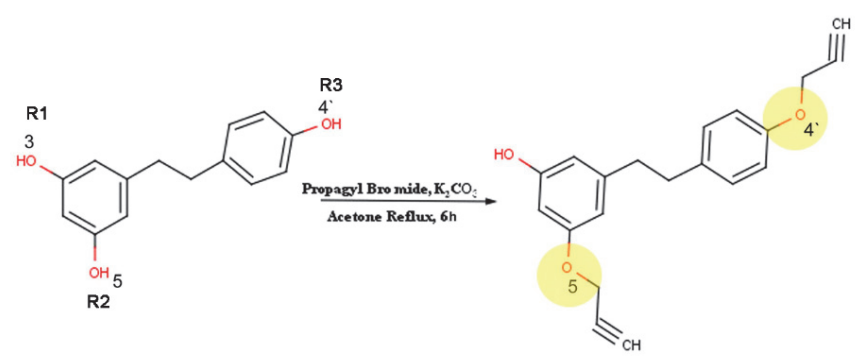

Fig. 1. Schematic representation of RESV-10 formation from RESV
By usage of the column chromatography method, the crude product was purified, after initial TLC monitoring and chloroform-MeOH (10/1) elution steps, (E)-3-(prop-2-yn-1yloxy)-5-(4-(prop-2-yn-1-yloxy) styryl) phenol was isolated as a colorless amorphous powder. $1 \mathrm{H} \mathrm{NMR}(400 \mathrm{MHz}, \mathrm{CDCl} 3) \delta$ ppm 2.05 (s, 1H), 2.54 (s, 1H), 4.70 (d, $J=4.20 \mathrm{~Hz}, 4 \mathrm{H}), 6.39$ (s, 1H), 6.78-6.51 (m, 2H), 7.10-6.78 (m, 4H), 7.44 (d, J = 8.09 $\mathrm{Hz}, 2 \mathrm{H}$ ) (Supplementary Fig. 1 and Fig. 2).

\section{Compound preparation for in vitro experiments}

RESV (Sigma-Aldrich 99\% purity; $100 \mathrm{mg}, 1 \mathrm{eq}$ ) and its newly synthesized analog were separately dissolved in dimethyl sulfoxide (DMSO; Sigma-Aldrich) at different concentrations $(1 \mu \mathrm{m} / \mathrm{ml}, 3 \mu \mathrm{m} / \mathrm{ml}, 5 \mu \mathrm{m} / \mathrm{ml}$ and $10 \mu \mathrm{m} / \mathrm{ml})$. The antitumor activity of the newly synthesized RESV in comparison to the native RESV compound investigated by cytotoxicity, DNA fragmentation, and anti-NF- $\mathrm{B}$ assays on the human U-937 cell line.

\section{Cytotoxicity assay}

The cytotoxic potential of RESV analog was tested on human histiocytic lymphoma (U-937) cell lines (American Type Culture Collection, Manassas, VA). The culturing of cell lines was done using RPMI 1640 media (Thermo Fisher Scientific) complemented with penicillin G (100 units/ml; Sigma-Aldrich), streptomycin $(100 \mu \mathrm{g} / \mathrm{ml}$; Sigma-Aldrich) and $10 \%$ pre-heated fetal bovine serum (Sigma-Aldrich). These cultures were kept at $37{ }^{\circ} \mathrm{C}$ humid atmosphere and incubated in a $\mathrm{CO}_{2}(5 \%)$ incubator. Both RESV and its analog were separately dissolved in DMSO and then further diluted with RPMI 1640 media to ensure $<0.5 \% v / v$ concentration of DMSO. U-937 cells were plated into 96-microwell plates at 10,000-20,000 cells/well and incubated for $24 \mathrm{~h}$. Then, $100 \mu \mathrm{l}$ of samples were introduced in triplicates to a final concentration of $0.1-200 \mu \mathrm{M}$. RESV and its synthetic analog were added in a different concentration of $1 \mu \mathrm{M}, 3 \mu \mathrm{M}, 5 \mu \mathrm{M}$ and $10 \mu \mathrm{M}$ per $\mathrm{ml}$ to all the cell samples. After further incubating cell samples for $48 \mathrm{~h}$, their viability was determined as per the following procedure. After the culture medium was discarded, $200 \mu \mathrm{l}$ of pre-warmed PBS solution was added to wash the cells thoroughly. Then, $200 \mu \mathrm{l}$ of MTT 3-(4,5-dimethylthiazol-2-yl)-2,5-diphenyltetrazolium bromide) (Sigma, St. Louis, MO, USA) in RPMI media was refreshed and microplates were placed back into the incubator to be kept for 1 to $2 \mathrm{~h}$ at $37^{\circ} \mathrm{C}$. After that step, the MTT containing media was carefully removed, and the cell washing step was done with pre-warmed PBS $(200 \mu \mathrm{l})$. DMSO $(100 \mu \mathrm{l})$ was added, and formazan crystals were dissolved under gentle shaking (30 min) (Campling et al., 1988). Absorbance at $540 \mathrm{~nm}$ was read with a microplate reader (FLUOstar optima). The number of viable cells was presented in the form of percentages. All the measurements were performed in triplicates. From the treated cell population, the number of viable cells against the total control population was expressed to calculate the \% cytoviability, following the formula: Cytoviability (\%) = $\left[\mathrm{A}_{540 \mathrm{~nm}}\right.$ of treated cells] $\times 100 \% /\left[\mathrm{A}_{540 \mathrm{~nm}}\right.$ of control cells $]$.

\section{DNA fragmentation assay}

The U-937 cells were seeded at the density of $1 \times 10^{6}$ in the 6 -well petri tissue culture plates and overnight incubated at $37^{\circ} \mathrm{C}$. The cells treated with $10 \mu \mathrm{M}$ RESV or its analog at a $10 \mu \mathrm{M}$ concentration in the culture medium. DMSO suspended cells were maintained as an internal control for all experiments $\left(1 \times 10^{6}\right.$ cells $)$. Then, after $48 \mathrm{~h}$, the dead cells from each well were removed in a tube, leaving adherent cells (live cells) in the $50 \mathrm{ml}$ tube. All the adherent cells were centrifuged 
for $5 \mathrm{~min}$, and the supernatant was removed. The cell pellet at the bottom was treated with $500 \mu \mathrm{l}$ of Lysis buffer $(50 \mathrm{mM}$ Tris-Hcl at pH 7.6, 10 mM EDTA, pH 8.0 and 0.5\% w/v Triton $\mathrm{X}$-100). The fragmented DNA was treated with $10 \mu \mathrm{l}$ RNAse $\left(37^{\circ} \mathrm{C}\right.$ for $2 \mathrm{~h}$ ) and $20 \mu \mathrm{l}$ Proteinase $\mathrm{K}\left(37^{\circ} \mathrm{C}\right.$ for $\left.2.5 \mathrm{~h}\right)$. The precipitation of DNA was done with isopropanol, further treated with $\mathrm{NaCl}$ and incubated for overnight at $-20{ }^{\circ} \mathrm{C}$. The isolated DNA fragments were separated on agarose (2\%) gel and visualized using a transilluminator machine. The propidium iodide staining of both treated and untreated U-937 cells was done to confirm the nuclear fragmentation status (Bonfoco et al., 1995).

\section{Anti NF- $\kappa$ B assay}

We have used EZ-Detect ${ }^{\mathrm{TM}}$ Transcription Factor Assay kit for assessing the ability of RESV compounds to interfere with the specific binding between biotinylated-consensus sequence and active form of NF- $\mathrm{B}, \mathrm{NF}-\kappa \mathrm{B}-\mathrm{p} 65$. In brief, the nuclear extractions of cells treated with different concentrations of RESV and TNF $\alpha$ were used to determine the binding affinity between NF- $\kappa B$ and p65. The nuclear extract of cells stimulated with TNFa has been used as a control. The NF- $\kappa$ B activity was calculated based on chemiluminescent signals measured in the microplate plate reader. All the results were expressed as $\mathrm{IC}_{50}$, which means the half-maximal inhibitory concentration of the query compound.

\section{Docking NF- $\kappa$ B with RESV analogs}

AutoDock 4.0 (Morris et al., 2008) program was used to execute a docking simulation between the drugs and proteins using a Lamarckian Genetic Algorithm method. Typical docking method for flexible ligands and rigid protein starts with the identification of torsion angles of the ligand using ten independent runs per ligand. The protein structure was charged by adding charged ions, and histidine molecules were neutralized in whole protein. Finally, Gasteiger charges were applied to neutralize the charges on the whole protein. The autogrid feature used to calculate the grid map of protein-ligand. The grid file, with parameters of $60 \times 60 \times 60$ points in $x, y$, and $z$ directions, and center grid spacing of $0.367 \AA$ ( $1 / 4^{\text {th }}$ of the length of $C-C$ covalent bond) was prepared. In the final stage, the docking file built on different types of parameters prepared with the help of the AutoDock tool. During the docking procedure, the ligand conformations were optimized by the Lamarckian genetic algorithm, and for each ligand, around 10 docking runs performed. The search algorithm set to a Lamarckian genetic algorithm with default genetic algorithm settings set to 150 runs, and with 150 possible conformations, 50 population sizes and 2,500,000 the energy evaluations. For docking parameters, the translation was set to $0.2 \AA$; the torsion to $0.5 \AA$; the quaternion to $5.0 \AA$; and the RMS cluster tolerance to $0.75 \AA$. At the end of docking, ligands with the maximum promising binding energy selected as the results from the protein-ligand docking complex. The resultant complex structures explored using the Pymol-0.98 program.

\section{Hex docking studies on NF- $\kappa B-R E S V$ analog and DNA complex}

The crystal structure of Human p65/p50 Heterodimer in complex with DNA was retrieved from PDB (Berman et al., 2002). The protein and DNA structures separated from each other by editing the PDB file. The geometric energy minimized NF- $\mathrm{BB}$ was first individually docked onto a DNA using Hex graphical interface web server (Macindoe et al., 2010) works based on Fast Fourier transform (FFT) docking algorithms. To get dif- ferent docking poses and binding energies in between receptor and ligand, a series of parameters like shape, electrostatic correlation parameter, grid dimension at $0.6 \AA$, FFT mode as 3D, ligand range at $180 \AA$, Receptor, and twist range $360 \AA$ were chosen from default settings, the docked complexes of NF- $\kappa$ BRESV analogs were redocked with DNA. The results provided by Hex docking gives random energy values which serve as the groove to determine the best fit model. The best docking complex was prioritized based on the highest negative order of their energy values (Shaik et al., 2018).

\section{Results}

\section{The screening of RESV analogs}

All the chemically designed RESV analogs were analyzed for their physicochemical properties like the number of hydrogen bond acceptors, molecular weight, miLogP value, number of rotatable bonds, and number of hydrogen bond donors. All these biophysical characteristics were evaluated against Lipinski's rule of five, which could predict the potential drug-likeliness of any query compound. According to Lipinski's rule of five molecular properties, a potential drug compound possesses a molecular weight of $\leq 500, \leq 10$ hydrogen bond acceptors, $\leq 5 \log \mathrm{P}$ value and $\leq 5$ hydrogen bond, donors. Therefore, we screened all the 50 RESV analogs against different parameters to judge the drug-likeness of RESV analogs. In this context, we found that 30 RESV analogs (out of 50 molecules designed) have shown their compliance towards the Lipinski's requirement for a potential drug compound (Table 1). During the preliminary screening step, we found that the general biophysical activity scores of all the 30 RESV compounds is as follows, MW is $351.45 \mathrm{kDa}, \mathrm{nON}$ is $<6, \mathrm{nOH} \mathrm{NH}$ is $\angle 5$, TPSA is $<105.77 \AA$, nrotb is $<8$, miLog $\mathrm{P}$ is $<7.98, \mathrm{~N}$ atoms is $<26$ and molecular volume is $<348 \mathrm{~g} / \mathrm{mol}$. The rotatable bonds determine the conformational changes of the drug molecules and also influence receptor-ligand binding characteristics. To pass oral bioavailability criteria for any potential drug molecule, the ideal number of rotatable bonds should be $<10$. The number of rotatable bonds for the RESV analogs designed in this study, were in 3-8 range, suggesting their potential drug behavior.

\section{Prediction studies of pharmacokinetic/toxicity characteristics}

The pharmacokinetics safety profile of the RESV analogs was predicted by ADME/Tox method. ADME property influences the level of drugs and drug kinetics in the tissues. The thirty RESV analogs screened in the previous stage were further analyzed for adsorption, distribution, excretion, metabolism, and toxicity with the help of the open source ADME/Tox web-box v3.5 tool. Table 3 reveals the prediction data of five RESV analogs which passed ADME/toxicity testing. The acid dissociation constant (PKa) of two RESV analogs (RESV-30 and RESV-40) denotes zwitterion property (basic and acidic groups with "0" value) and remaining three molecules (RESV10, RESV-14, RESV-25) indicates basic dissociation constant as " 0 " and acidic dissociation constant ranging between 9.5 and 9.84. The aqueous solubility ( $\log S W$ ) of these five designed analogs ranged in between $0.06 \mu \mathrm{g} / \mathrm{ml}$ and $0.13 \mathrm{mg} / \mathrm{ml}$. By using the Novel GALAS (Global, Adjusted Locally According to Similarity) modeling methodology. The reliability index (RI), metrics of solubility value of all the query the compounds is more than 0.5 , confirming their good solubility property in an aqueous environment. The predicted oral bioavailability of all the selected five analogs (RESV-10, RESV-14, RESV-25, 
RESV-30 and RESV-40) is greater than 54\%. Whereas one of the designed analog (RESV-10) has shown the highest oral bioavailability, which is more than $90 \%$, and it is predicted to have a greater rate of metabolism compared to the parental RESV compound. The predicted plasma protein binding (\%PPBS) of RESV analogs was in between 20 to 55\%. Among the five analogs, for RESV-10 the $\mathrm{LD}_{50}$ value was around $958 \mathrm{mg} / \mathrm{kg}$ for mouse, and $\mathrm{LD}_{50}$ was $1025 \mathrm{mg} / \mathrm{kg}$ for the rat. Among the five-best screened RESVanalogs, RESV-10 is found to be at the top position based on the important ADMET properties like bioavailability, \%PPBS, and Acute toxicity $\mathrm{LD}_{50}$ (Table 2). Therefore, RESV 10 analog was selected for further analysis by the docking method and in vitro assays.

Table 2. ADME and toxicity prediction data of the RESV synthetic analogs. The best analog is shown in the bold letters

\begin{tabular}{|c|c|c|c|c|c|c|c|c|c|c|c|}
\hline \multirow{2}{*}{$\begin{array}{l}\text { RESV- } \\
\text { analog }\end{array}$} & \multicolumn{2}{|c|}{ Solubility } & \multicolumn{4}{|c|}{ Physico-chemical determinants } & \multirow{2}{*}{$\begin{array}{c}\text { \% Oral } \\
\text { bioavaila- } \\
\text { bility }\end{array}$} & \multicolumn{2}{|c|}{ Distribution } & \multirow{2}{*}{$\begin{array}{c}\text { Acute } \\
\text { toxicity } \\
\mathrm{LD}_{50} 5 \\
\text { Mouse } \\
(\mathrm{mg} / \mathrm{kg}) \\
\text { Oral }\end{array}$} & \multirow{2}{*}{$\begin{array}{c}\text { Acute } \\
\text { toxicity } \\
\mathrm{LD}_{50} \mathrm{Rat} \\
(\mathrm{mg} / \mathrm{Kg}) \\
\text { Oral }\end{array}$} \\
\hline & $\begin{array}{l}\text { Water } \\
\text { (LogSw) }\end{array}$ & $\begin{array}{c}\text { Buffer } \\
(\mathrm{pH} 7.4) \\
\text { LogS }\end{array}$ & $\log D^{1}$ & $\log \mathrm{P}^{2}$ & $\begin{array}{l}\mathrm{Pka}^{3} \\
\text { (Acid) }\end{array}$ & $\begin{array}{c}\text { Pka } \\
\text { (Base) }\end{array}$ & & $\begin{array}{l}\text { Plasma } \\
\text { Protein } \\
\text { Binding }\end{array}$ & $\begin{array}{c}\mathrm{Vd}^{4} \\
(\mathrm{~L} / \mathrm{Kg})\end{array}$ & & \\
\hline RESV & -2.19 & -2.05 & 2.59 & 2.59 & 9.40 & 0 & $<70 \%$ & $70.97 \%$ & 1.84 & 920 & 870 \\
\hline RESV-10 & -4.37 & -4.30 & 4.05 & 4.05 & 9.60 & $\mathbf{0}$ & $<90 \%$ & $20.48 \%$ & 2.55 & 958 & 1025 \\
\hline RESV-14 & -2.85 & -2.55 & 3.33 & 3.33 & 9.5 & 0 & $<54 \%$ & $55.18 \%$ & 2.1 & 920 & 590 \\
\hline RESV-25 & -2.79 & -2.68 & 1.62 & 1.60 & 9.84 & 0 & $<78 \%$ & $58.47 \%$ & 1.45 & 450 & 282 \\
\hline RESV-30 & -4.25 & -4.25 & 3.28 & 3.25 & - & 0 & $<70 \%$ & $48.58 \%$ & 1.87 & 485 & 1027 \\
\hline RESV-40 & -2.20 & -2.20 & 4.56 & 4.56 & - & 0 & $<77 \%$ & $45.58 \%$ & 2.54 & 878 & 5470 \\
\hline
\end{tabular}

Note: ${ }^{1}$ LogD, Distribution coefficient; ${ }^{2} \log$ P, Partition coefficient; ${ }^{3}$ Pka, Dissociation constant; ${ }^{4}$ Vd, Volume of distribution; ${ }^{5} \mathrm{LD}_{50}$, Lethal dose

\section{MTT assay}

Immortalized U-937 cells treated with both native RESV and RESV-10 showed decreased cell viability. When U-937 cells were treated with RESV for $48 \mathrm{~h}$ at doses ranging from 1 to $10 \mu \mathrm{M}$, the cell viability was seen to be decreased with an increasing dose of the treatment. As shown in Fig. 2, RESV and RESV-10 treatment on U-937 cells resulted in a dose-dependent inhibition of cell growth with an $\mathrm{IC}_{50}$ value of $30 \mu \mathrm{M}$ and $7.25 \mu \mathrm{M}$, respectively. The higher cytotoxic activity RESV-10 analog is predicted due to the capping for $\mathrm{OH}$ groups at positions 5, 4'. Thus, MTT assay has confirmed the increased activity of RESV-10 in comparison to the RESV parental molecule.

\section{DNA fragmentation assay}

To examine if cell death is mediated by RESV-10 analog, we performed a DNA fragmentation assay, which is a good indicator of apoptosis. As shown in agarose gel electrophoresis of U-937 cells treated with $10 \mu \mathrm{M}$ of RESV and RESV-10, a typical ladder pattern of internucleosomal fragmentation was observed (Fig. 3). But control cells did not show any evidence

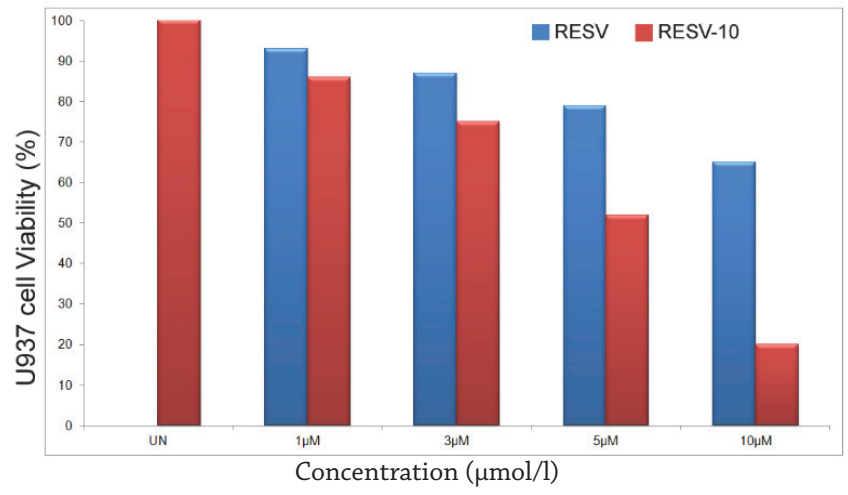

Fig. 2. MTT uptake \% of death of U937 cells with different concentrations of RESV and its analog RESV-10 of fragmentation. However, the cells treated with RESV-10 showed intense fragmentation compared to the native RESV compound. The breakdown of DNA is considered as a sign of inhibition of DNA due to internucleosomal cleavage associated with apoptosis. This data suggest that RESV-10 is a potent inducer of apoptosis in U-937 cells. This character is predictable due to the increased bioavailability of the RESV-10 as a result of decreased free hydroxyl groups.

\section{Anti NF- $\kappa$ B assay of RESV}

The chemically synthesized RESV analog was tested for its NF- $\mathrm{BB}$ inhibitory activity in U-937 cells. The target based inhibition of RESV-10 was significant at a concentration of $10 \mu \mathrm{g} / \mathrm{ml}$ with an $\mathrm{IC}_{50}$ value of 2.45 . At the same $10 \mu \mathrm{g} / \mathrm{ml}$ concentration, the native RESV compound shows the target-based inhibition activity with an $\mathrm{IC}_{50}$ value of 1.95 . Thus, based on our results, it is evident that RESV-10 successfully targets $\mathrm{NF}-\kappa \mathrm{B}$ and inhibits its action much better than the native RESV compound (Table 3).

\section{Molecular docking studies}

During the docking analysis, RESV was found to interact with the DNA binding residues of $\mathrm{p} 50$ chain in NF- $\kappa \mathrm{B}$. The RESV forms $3 \mathrm{H}$-bonds with $\mathrm{Lys}^{572}$, Gln ${ }^{574}$, and $\mathrm{Arg} 605$ with an

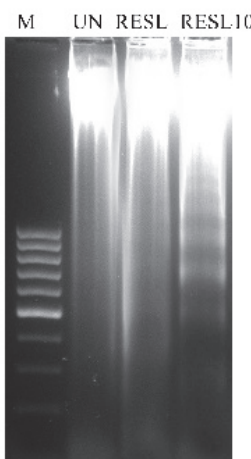

Fig. 3. Fragmentation of genomic DNA in cells after treatment for $48 \mathrm{~h}$ with $10 \mu \mathrm{m}$ concentration of RESV and its analogs RESV-10 
average distance of $3.35 \AA$. (Fig. 4). The ranking of binding energies for RESV with NF- $\kappa$ B p50 is $-6.12 \mathrm{kcal} / \mathrm{mol}$ at $32 \mu \mathrm{M}$ of Ki. Whereas, the RESV analog, (E)-3-(prop-2-yn-1-yloxy)-5(4-(prop-2-yn-1-yloxy) styryl) phenol groups forms $3 \mathrm{H}$-bonds with $\operatorname{Arg}^{246}(\mathrm{~A})$, Lys $444(B)$ and $G \ln 606(\mathrm{~B})$ with the average dis- tance of $2.05 \AA$ (Table 3). The binding of RESV-10 with the $\mathrm{NF}-\kappa \mathrm{B}$ demonstrated maximum binding energies of -6.78 $\mathrm{kcal} / \mathrm{mol}$ and Ki $10 \mu \mathrm{M}$ (Fig. 5). Thus, the RESV-10 analog has established strong interactions with NF- $\mathrm{BB}$ compared to native RESV.

Table 3. Docking energies of RESV and RESV-10 with NF- $\mathrm{B}$

\begin{tabular}{|c|c|c|c|c|c|c|c|}
\hline $\begin{array}{l}\text { Protein- } \\
\text { compound }\end{array}$ & $\mathrm{RMSD}^{\mathrm{a}}$ & $\begin{array}{c}\text { Binding } \\
\text { energy }^{\mathrm{b}} \\
(\mathrm{kcal} / \mathrm{mol})\end{array}$ & $\begin{array}{c}\text { Inhibition } \\
\text { constant }^{c} \\
(K i)\end{array}$ & $\begin{array}{c}\text { Number of } \\
\text { H-bonds } \\
\text { (drug-enzyme) }\end{array}$ & Amino acids & $\begin{array}{c}\text { H-bond } \\
\text { distance } \\
\AA\end{array}$ & $\begin{array}{c}\text { NF- } \kappa \mathrm{B} \\
\text { Experimental } \\
\mathrm{IC}_{50} \\
10 \mu \mathrm{g} / \mathrm{ml} \\
\end{array}$ \\
\hline NF- $\kappa B-R E S V$ & 1.256 & -6.12 & $32 \mu \mathrm{M}$ & 4 & $\begin{array}{l}\operatorname{Lys}^{572(B)} \\
\mathrm{Gln}^{574(B)} \\
\operatorname{Arg}^{605}(\mathrm{~B})\end{array}$ & $\begin{array}{l}3.35 \\
3.40 \\
3.31\end{array}$ & 1.95 \\
\hline NF- $\kappa B-R E S V-10$ & 0.458 & -6.78 & $10 \mu \mathrm{M}$ & 3 & $\begin{array}{l}\operatorname{Arg}^{246}(\mathrm{~A}) \\
\mathrm{Lys}^{444}(\mathrm{~B}) \\
\mathrm{Gln}^{606}(\mathrm{~B})\end{array}$ & $\begin{array}{l}2.15 \\
1.95 \\
2.05\end{array}$ & 2.45 \\
\hline
\end{tabular}

a The root-mean-square deviation of heavy atoms with respect to the experimental structure.

$\mathrm{b}$ The change in binding free energy is related to the inhibition constant using the equation:

$\Delta \mathrm{G}=R T$ in $K i$, where $\mathrm{R}$ is the gas constant $1.987 \mathrm{cal} \mathrm{K}^{-1} \mathrm{~mol}^{-1}$, and $\mathrm{T}$ is the absolute temperature assumed to be $298.15 \mathrm{~K}$.

${ }^{\mathrm{c}} K i=\exp \left(\Delta \mathrm{G} / \mathrm{R}^{*} \mathrm{~T}\right)\left[\Delta \mathrm{G}\right.$ binding $=-\mathrm{R}^{*} \mathrm{~T}^{*} \mathrm{Ln} \mathrm{Kb} ; \Delta \mathrm{G}$ inhibition $=\mathrm{R}^{*} \mathrm{~T}^{*} \mathrm{Ln} K i(\Delta \mathrm{G}=$ Free energy; $\mathrm{R}=\mathrm{Gas}$ constant; $\mathrm{T}=\mathrm{Absolute}$ temperature; Ln $\mathrm{K}=$ Equilibrium constant)].

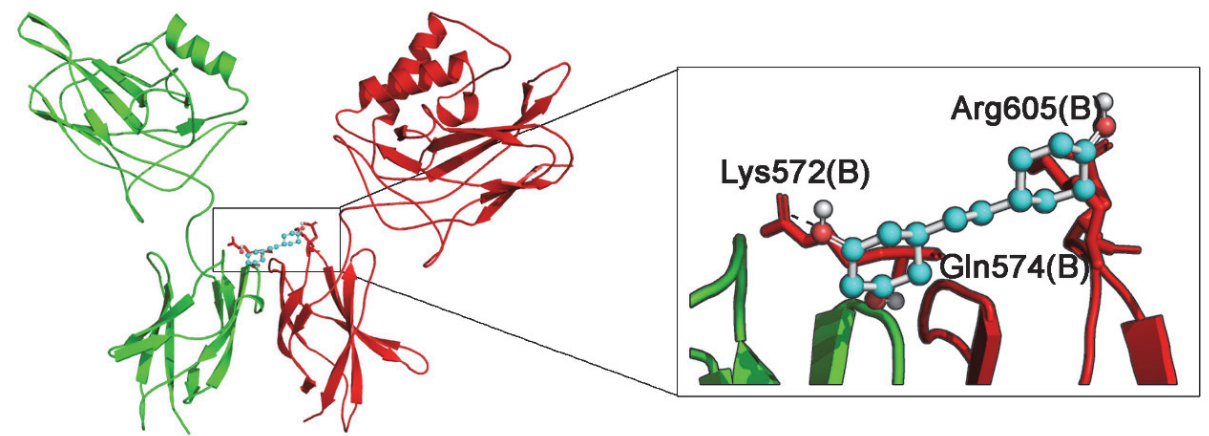

Fig. 4. Interaction of RESV with NF- $\mathrm{B}$ DNA (p65(A) red and p50(B) green in colour) binding site [Dotted lines indicate the potential hydrogen bonding between $\operatorname{Lys}^{572(B), ~ G l n}{ }^{574}(B)$ and $\operatorname{Arg}^{605}(B)$ with RESV]

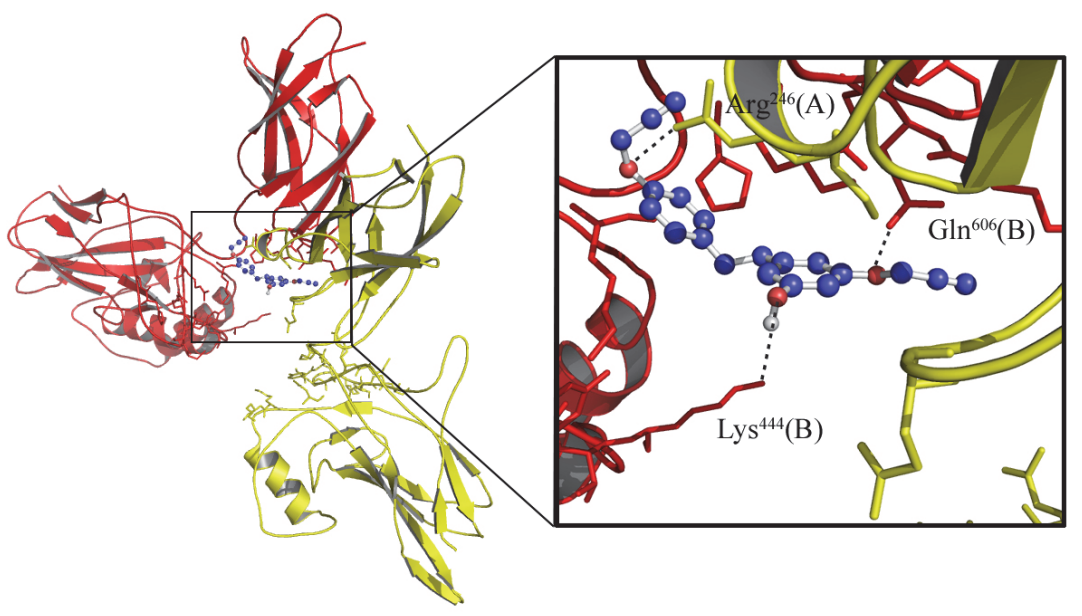

Fig. 5. Binding mode of RESV-10 to NF- $\mathrm{kB}$ (p65(A) red and p50(B) yellow in colour). The black dotted lines indicate the potential hydrogen bonding between $\operatorname{Arg}^{246}(\mathrm{~A}), \mathrm{Lys}^{444}(\mathrm{~B})$, and $\mathrm{Gln}{ }^{606}$ (B) with RESV-10 


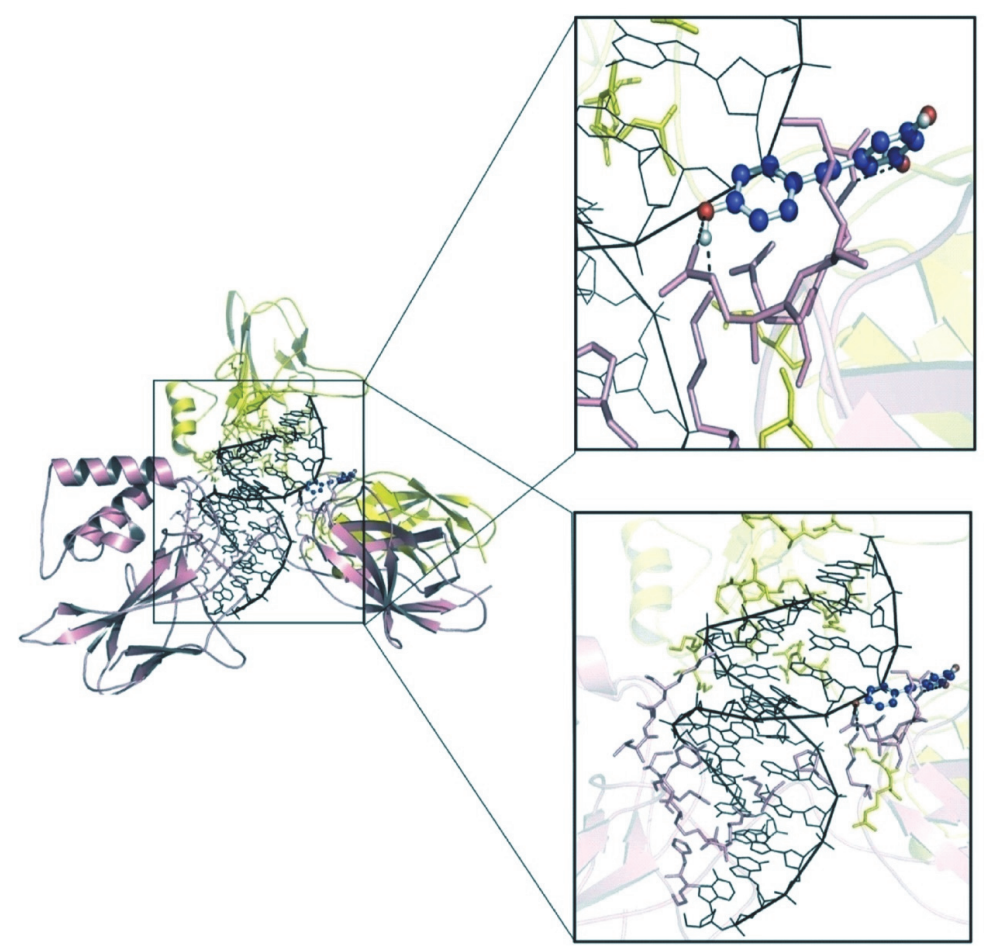

Fig. 6. Molecular Docking of NF-kB-RESV and DNA. Top zoom view shows the binding mode of RESV with NF- $\mathrm{kB}$ at DNA binding site, and bottom zoom view shows the binding of DNA with NF-kB-RESV complex

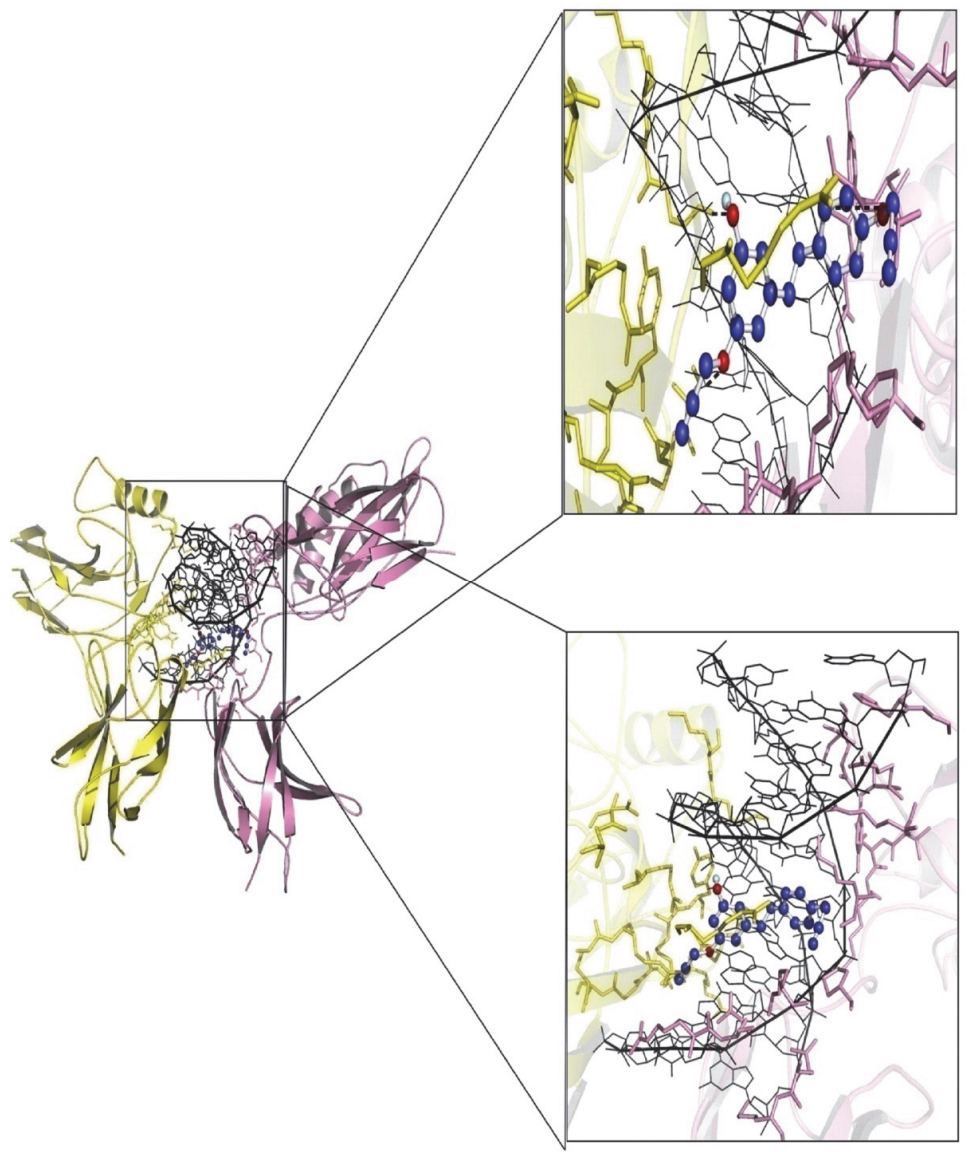

Fig. 7. Molecular Docking of NF-kB-RESV-10 and DNA, top zoom view shows the binding mode of RESV-10 with NF- $\mathrm{kB}$ at DNA binding site, and bottom zoom view shows the binding of DNA with NF-kB-RESV-10 complex 


\section{Docking complex (NF- $\kappa B-R E S V$ and NF- $\kappa B-R E S V-10)$ with DNA}

Three different molecular interaction analyses of NF- $\kappa B$ performed by using Hex docking server; wherein the first step involved the docking between DNA and NF- $\mathrm{B}$, followed by two separate docking steps one with NF- $\mathrm{B}$ + RESV complex with DNA and the second one with NF- $\kappa B+$ RESV-10 complex with DNA. The probe of DNA (5'-GGGACTTTCCGCTGGGGACTTT-3') retrieved from the crystal structure of NF-kB (PDB ID: $3 G U T$ ) was docked with energy minimized non-ligand NF- $\mathrm{B}$. This probe sequence represents a consensus binding site for the human nuclear factor kappaB (NF- $\kappa \mathrm{B})$ binding site. The Hex docking results explored the DNA binding site of NF- $\kappa B$ heterodimer (p65/p50), which interacts strongly with the DNA segment and releases the total energy of $-3005.72 \mathrm{kcal} /$ mol (Table 4). The docking complex of NF- $\kappa B$-DNA superimposed in crystal structure had shown a root mean square deviation (RMSD) value of $0 \mathrm{~nm}$, confirming the accuracy of docking analysis. The docked complex of NF- $\mathrm{kB}-\mathrm{RESV}$ after redocking with DNA, showed a decrease in the total energy value to $-150.4 \mathrm{kcal} / \mathrm{mol}$, due to the strong $\mathrm{H}$-bond interaction of RESV with DNA binding residues of NF- $\kappa B$ (Fig. 6). Similarly, the redocking of docked complexes of NF- $\kappa B / R E S V-10$ with DNA resulted in the release of docking energy of $-139.8 \mathrm{kcal} /$ mol. (Fig. 7, Table 4). This result demonstrates that due to the binding of RESV and RESV-10 at the DNA binding site of NF$\kappa \mathrm{B}$, there is an increase in the degree of orientation of residues. Thus, there is a weak interaction in the DNA of cells treated with RESV and its analogs in comparison to the normal cell.

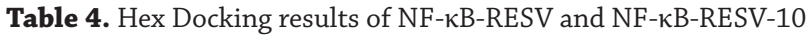
binding with DNA

\begin{tabular}{|c|c|c|c|}
\hline S.No. & Molecules & $\mathrm{RMS}^{\mathrm{a}}$ & $\begin{array}{c}\text { E-total } \\
\mathrm{kcal} / \mathrm{mol}^{\mathrm{b}}\end{array}$ \\
\hline 1 & NF- & 2.02 & -717.90 \\
\hline 2 & $\begin{array}{c}\text { NF-kB-RESV Complex with } \\
\text { DNA }\end{array}$ & 2.85 & -150.40 \\
\hline 3 & $\begin{array}{l}\text { NF-kB RESV-10 complex } \\
\text { with DNA }\end{array}$ & 1.25 & -139.8 \\
\hline
\end{tabular}

Note: ${ }^{\mathrm{a}} \mathrm{RMS}$, root mean square deviation from the reference structure; ${ }^{\mathrm{b}}$ E-total, total binding energy

\section{Discussion}

In one past study, by replacing the alkene linker in between 2 aromatic rings with the heterocyclic system, a rigid analog such as 2,3-thiazolidin-4-ones and 3-chloro-azetidin-2-ones, which has higher ability to inhibit in vitro breast cancer cell growth has been synthesized (Chimento et al., 2016). Another study has also proposed two novel RESV analogs i.e. 4-(E)-[(4-hydroxyphenylimino)-methylbenzene, 1, 2-diol)] (HPIMBD) and 4-(E)-[(p-tolylimino)-methylbenzene-1,2diol)] (TIMBD) acts as potent antioxidants against breast cancer (Bommagani et al., 2019; Licznerska et al., 2017). Some studies have prepared new polyhydroxylated RESV derivatives (3,3',4,5,5'-pentahydroxy-trans-stilbene) with clinical poten- tial for human colon cancer chemotherapy (Chatterjee et al., 2018; Li et al., 2019).

In the current investigation, we have modified the functional groups of RESV and designed 50 different chemical derivatives of RESV compound intending to increase its bioavailability and enhance the NF- $\mathrm{kB}$ target specificity in U-937 cells. The presence of an -OH group at the C3, C5, and C4' positions in RESV (5-[(E)-2-(4-hydroxyphenyl) ethenyl] benzene-1,3-diol) $\left(\mathrm{C}_{14} \mathrm{H}_{12} \mathrm{O}_{3}\right)$ did not favor the bioavailability of RESV. The circulating free hydroxyl RESV shows a serum half-life of 8-14 min and will be rapidly metabolized in carbohydrate catabolism pathways (Marier et al., 2002). Hence, the capping of free $\mathrm{OH}$ groups or the introduction of polar groups, such as hydroxy or methoxy, around the phenolic -OH group of RESV is likely to enhance bioactivity. Previously, it was reported that the addition of methoxy, alkyl, ethyl, etc., group around phenolic-OH group had shown a higher rate of potential activity in different types of cancer cells compared to parental RESV (Piotrowska et al., 2012). In the RESV-10, (E)-3-(prop-2-yn-1yloxy)-5-(4-(prop-2-yn-1-yloxy)styryl)phenol analog, an additional reactive group i.e. $\mathrm{CH} 2-\mathrm{CH} \equiv \mathrm{CH}$ (But-1-yne) at 5, 4' -OH group appears to have favored the bioavailability and antiNF- $\mathrm{KB}$ activity in cancer cells.

The RESV-10 derivative has demonstrated increased bioavailability of up to $90 \%$ compared to native RESV (up to $70 \%$ ) compound. Furthermore, RESV-10 showed better plasma protein binding potential $(<20.48 \%)$, which reflects its increased ability to diffuse across cell membranes by reducing its interaction with albumin, glycoprotein, and lipoproteins. The half of maximal lethal dose $\left(\mathrm{LD}_{50}\right)$ values can be viewed as an indication of the "cumulative potential" to cause various acute effects and death of animals and are the most widely used measure of the "acute systemic toxicity" of the chemical. The increased oral bioavailability and low $\mathrm{LD}_{50}$ are characteristics of much safer drugs in targeting human diseases (Stuurman et al., 2013). The $\mathrm{LD}_{50}$ of RESV-10 is around $958 \mathrm{mg} / \mathrm{kg}$ for mouse, and $\mathrm{LD}_{50}$ was $1025 \mathrm{mg} / \mathrm{kg}$ for the rat. The current study findings support that RESV-10 shows better ADME-tox properties that are bioavailability, PPBS, and Acute toxicity $\mathrm{LD}_{50}$ compared to native RESV compound.

$\mathrm{NF}-\kappa \mathrm{B}$ signaling regulates cell proliferation and apoptosis (Hayden and Ghosh, 2012). NF- $\kappa B$ forms complex heteromeric structure with p50, p65, and IkB-alpha, and predominantly resides in the cytoplasm in an inactive state. When $\mathrm{IkB}$ is degraded by phosphorylation and ubiquitination, $\mathrm{NF}-\kappa \mathrm{B}$ proteins translocate to the nucleus and binds to the B site (GGGPuNNPyPyCC consensus site) of DNA to modulate target gene expression. RESV can suppress NF- $\kappa B$ activation by blocking the activation of IkB (Adhami et al., 2003). Through molecular docking analysis, we have found that RESV10 forms 3 hydrogen bond interactions (at Arg246, Lys444 and Gln ${ }^{606}$ ) with NF-kB at DNA binding residues of the p50 chain. The RESV-10 derivative shows more affinity $(-6.12 \mathrm{kcal} / \mathrm{mol}$ at $32 \mu \mathrm{M}$ of $\mathrm{Ki}$ ) with NF- $\mathrm{KB}$ compared to the native RESV compound $(-6.78 \mathrm{kcal} / \mathrm{mol}$ and $10 \mu \mathrm{M}$ of $\mathrm{Ki})$, which interacts with Lys ${ }^{572}, \mathrm{Gln}^{574}$, and Arg605 amino acids. In our previous investigation, a fairly good agreement between computational molecular docking analysis and experimental findings was observed. A better affinity of a novel RESV analogue (E)-5-(4-acetoxystyryl)-1,3-phe-nylene diacetate) towards DNA binding amino acid residues of NFkB compared to native RESV compound was observed (Banaganapalli et al., 2013). 


\section{Conclusions}

In this study, we developed a new RESV analog (RESV-10) with increased bioavailability and potential anticancer activity against U-937 cells compared to parental RESV. Synthesis of RESV-10 was performed by substitution of two hydroxyl groups on RESV-10 and the addition of propynyl groups on 5, 4' OH groups. Capping of these hydroxyl groups on 5, 4' positions of RESV-10 increased the half-life period and bioavailability of the compound. This chemical modification has increased the anti-proliferation activity of RESV-10 when compared with RESV, treated cells. Even the activity of $\mathrm{NF}-\kappa \mathrm{B}$ is decreased in U-937 cells when they are treated with RESV-10. Our in vitro experimental results confirmed the findings of computational molecular docking which revealed that the RESV-10 had increased affinity to bind with DNA binding site of NF- $\kappa \mathrm{B}$, hence preventing the interactions between DNA with NF- $\kappa$ B molecule. Thus RESV-10 may be a new promising candidate against cancer. Due to the complexity and number of cellular processes where the NF- $\mathrm{KB}$ molecule is involved, more studies must be performed to completely understand how resveratrol and analogs could be used to prevent the development of cancer.

\section{Conflict of interests}

Authors declare no conflict of interests for this article.

\section{Funding and acknowledgements}

This project was funded by the Deanship of Scientific Research (DSR) at King Abdulaziz University, under Grant no. G-499140-1439. The authors, therefore, acknowledge the DSR for technical and financial support.

\section{References}

Adhami VM, Afaq F, Ahmad N (2003). Suppression of ultraviolet B exposure-mediated activation of NF-kappaB in normal human keratinocytes by resveratrol. Neoplasia 5: 74-82.

Almeida L, Vaz-da-Silva M, Falcao A, Soares E, Costa R, Loureiro AI, et al. (2009). Pharmacokinetic and safety profile of transresveratrol in a rising multiple-dose study in healthy volunteers. Mol Nutr Food Res 53(Suppl. 1): S7-15. DOI: 10.1002/ mnfr.200800177.

Banaganapalli B, Mulakayala C, Pulaganti M, Mulakayala N, Anuradha CM, Suresh Kumar C, et al. (2013). Experimental and computational studies on newly synthesized resveratrol derivative: a new method for cancer chemoprevention and therapeutics? OMICS 17: 568-583. DOI: 10.1089/omi.2013.0014.

Berman AY, Motechin RA, Wiesenfeld MY, Holz MK (2017). The therapeutic potential of resveratrol: a review of clinical trials. NPJ Precis Oncol 1: 35. DOI: 10.1038/s41698-017-0038-6.

Berman HM, Battistuz T, Bhat TN, Bluhm WF, Bourne PE, Burkhardt K, et al. (2002). The Protein Data Bank. Acta Crystallogr D Biol Crystallogr 58(Pt 6 NO 1): 899-907. DOI: 10.1107/ s0907444902003451.

Bommagani S, Penthala NR, Balasubramaniam M, Kuravi S, CaldasLopes E, Guzman ML, et al. (2019). A novel tetrazole analogue of resveratrol is a potent anticancer agent. Bioorg Med Chem Lett 29: 172-178. DOI: 10.1016/j.bmcl.2018.12.006.

Bonfoco E, Krainc D, Ankarcrona M, Nicotera P, Lipton SA (1995). Apoptosis and necrosis: two distinct events induced, respectively, by mild and intense insults with N-methyl-D-aspartate or nitric oxide/superoxide in cortical cell cultures. Proc Natl Acad Sci U S A 92: 7162-7166. DOI: 10.1073/pnas.92.16.7162.
Campling BG, Pym J, Galbraith PR, Cole SP (1988). Use of the MTT assay for rapid determination of chemosensitivity of human leukemic blast cells. Leuk Res 12: 823-831. DOI: 10.1016/01452126(88)90036-7.

Chatterjee A, Ronghe A, Padhye SB, Spade DA, Bhat NK, Bhat HK (2018). Antioxidant activities of novel resveratrol analogs in breast cancer. J Biochem Mol Toxicol 32. DOI: 10.1002/jbt.21925.

Chimento A, Sirianni R, Saturnino C, Caruso A, Sinicropi MS, Pezzi V (2016). Resveratrol and Its Analogs As Antitumoral Agents For Breast Cancer Treatment. Mini Rev Med Chem 16(9): 699-709. DOI: 10.2174/1389557516666160321113255.

Cottart CH, Nivet-Antoine V, Laguillier-Morizot C, Beaudeux JL (2010). Resveratrol bioavailability and toxicity in humans. Mol Nutr Food Res 54: 7-16. DOI: 10.1002/mnfr.200900437.

DiDonato JA, Mercurio F, Karin M (2012). NF-kappaB and the link between inflammation and cancer. Immunol Rev 246: 379-400. DOI: 10.1111/j.1600-065X.2012.01099.x.

Hayden MS, Ghosh S (2012). NF-kappaB, the first quarter-century: remarkable progress and outstanding questions. Genes Dev 26: 203-234. DOI: 10.1101/gad.183434.111.

Kadry MO, Abdel-Megeed RM, El-Meliegy E, Abdel-Hamid AZ (2018). Crosstalk between GSK-3, c-Fos, NF-kappaB and TNFalpha signaling pathways play an ambitious role in Chitosan Nanoparticles Cancer Therapy. Toxicol Rep 5: 723-727. DOI: 10.1016/j.toxrep.2018.06.002.

Koch PD, Miller HR, Yu G, Tallarico JA, Sorger PK, Wang Y, et al. (2018). A High Content Screen in Macrophages Identifies Small Molecule Modulators of STING-IRF3 and NF- $\mathrm{kB}$ Signaling. ACS Chem Biol 13: 1066-1081 DOI: 10.1021/acschembio.7b01060.

Li H, Wu WK, Zheng Z, Che CT, Li ZJ, Xu DD et al. (2010). 3,3',4,5,5'-Pentahydroxy-trans-stilbene, a resveratrol derivative, induces apoptosis in colorectal carcinoma cells via oxidative stress. Eur J Pharmacol 637: 55-61 DOI: 10.1016/j.ejphar.2010.04.009.

Li QS, Li Y, Deora GS, Ruan BF (2019). Resveratrol and Its Analogues: Recent Advances in Structural Modification and Bioactivity. Mini Rev Med Chem. 19(10): 809-825. DOI: 10.2174/1389557519666 190128093840.

Licznerska B, Szaefer H, Wierzchowski M, Sobierajska H, BaerDubowska W (2017). Resveratrol and its methoxy derivatives modulate the expression of estrogen metabolism enzymes in breast epithelial cells by AhR down-regulation. Mol Cell Biochem 425: 169-179. DOI: 10.1007/s11010-016-2871-2.

Lipinski CA (2004). Lead- and drug-like compounds: the ruleof-five revolution. Drug Discov Today Technol 1: 337-341. DOI: 10.1016/j.ddtec.2004.11.007.

Mabkhot YN, Alatibi F, El-Sayed NN, Al-Showiman S, Kheder NA, Wadood A, et al. (2016). Antimicrobial Activity of Some Novel Armed Thiophene Derivatives and Petra/Osiris/ Molinspiration (POM) Analyses. Molecules 21(2). DOI: 10.3390/ molecules21020222.

Macindoe G, Mavridis L, Venkatraman V, Devignes MD, Ritchie DW (2010). HexServer: an FFT-based protein docking server powered by graphics processors. Nucleic Acids Res 38: W445-449. DOI: $10.1093 / \mathrm{nar} / \mathrm{gkq} 311$.

Marier JF, Vachon P, Gritsas A, Zhang J, Moreau JP, Ducharme MP (2002). Metabolism and disposition of resveratrol in rats: extent of absorption, glucuronidation, and enterohepatic recirculation evidenced by a linked-rat model. J Pharmacol Exp Ther 302: 369-373. DOI: 10.1124/jpet.102.033340.

Martinez GP, Mijares MR, Chavez K, Suarez AI, Compagnone RS, Chirinos P, et al. (2019). Caracasine acid, an ent-3,4-seco-kaurene, promotes apoptosis and cell differentiation through NFkB signal pathway inhibition in leukemia cells. Eur J Pharmacol 862: 172624. DOI: 10.1016/j.ejphar.2019.172624.

Morris GM, Huey R, Olson AJ (2008). Using AutoDock for ligandreceptor docking. Curr Protoc Bioinformatics Chapter 8: Unit 8. 14. DOI: $10.1002 / 0471250953 . b i 0814 s 24$.

Ogas T, Kondratyuk TP, Pezzuto JM (2013). Resveratrol analogs: promising chemopreventive agents. Ann N Y Acad Sci 1290: 21-29. DOI: 10.1111/nyas.12196.

Pangeni R, Sahni JK, Ali J, Sharma S, Baboota S (2014). Resveratrol: review on therapeutic potential and recent advances 
in drug delivery. Expert Opin Drug Deliv 11: 1285-1298. DOI: 10.1517/17425247.2014.919253.

Piotrowska H, Myszkowski K, Ziolkowska A, Kulcenty K, Wierzchowski M, Kaczmarek M, et al. (2012). Resveratrol analogue 3,4,4',5-tetramethoxystilbene inhibits growth, arrests cell cycle and induces apoptosis in ovarian SKOV-3 and A-2780 cancer cells. Toxicol Appl Pharmacol 263: 53-60. DOI: 10.1016/j. taap.2012.05.023.

Sander T, Freyss J, von Korff M, Reich JR, Rufener C (2009). OSIRIS, an entirely in-house developed drug discovery informatics system. J Chem Inf Model 49: 232-246. DOI: 10.1021/ci800305f.

Sergides C, Chirila M, Silvestro L, Pitta D, Pittas A (2016). Bioavailability and safety study of resveratrol $500 \mathrm{mg}$ tablets in healthy male and female volunteers. Exp Ther Med 11: 164-170. DOI: 10.3892/etm.2015.2895.

Shaik NA, Awan ZA, Verma PK, Elango R, Banaganapalli B (2018). Protein phenotype diagnosis of autosomal dominant calmodulin mutations causing irregular heart rhythms. J Cell Biochem 119: 8233-8248. DOI: $10.1002 / j c b .26834$.

Shanmuganathan S, Angayarkanni N (2018). Chebulagic acid Chebulinic acid and Gallic acid, the active principles of Triphala, inhibit TNFalpha induced pro-angiogenic and pro-inflammatory activities in retinal capillary endothelial cells by inhibiting p38, ERK and NF- $\mathrm{KB}$ phosphorylation. Vascul Pharmacol 108: 23-35. DOI: 10.1016/j.vph.2018.04.005
Stuurman FE, Nuijen B, Beijnen JH, Schellens JH (2013). Oral anticancer drugs: mechanisms of low bioavailability and strategies for improvement. Clin Pharmacokinet 52: 399-414. DOI: 10.1007/s40262-013-0040-2.

Tian B, Liu J (2019). Resveratrol: A review of plant sources, synthesis, stability, modification and food application. J Sci Food Agric. DOI: 10.1002/jsfa.10152.

Walle T, Hsieh F, DeLegge MH, Oatis JE, Jr., Walle UK (2004). High absorption but very low bioavailability of oral resveratrol in humans. Drug Metab Dispos 32: 1377-1382. DOI: 10.1124/ dmd.104.000885.

Yang C, Wang Y, Xie Y, Liu G, Lu Y, Wu W, et al. (2019). Oat proteinshellac nanoparticles as a delivery vehicle for resveratrol to improve bioavailability in vitro and in vivo. Nanomedicine (Lond). DOI: 10.2217/nnm-2019-0244.

Zhang Y, Yang S, Yang Y, Liu T (2019). Resveratrol induces immunogenic cell death of human and murine ovarian carcinoma cells. Infect Agent Cancer 14: 27. DOI: 10.1186/s13027-0190247-4.

Zhou L, Qi L, Jiang L, Zhou P, Ma J, Xu X, et al. (2014). Antitumor activity of gemcitabine can be potentiated in pancreatic cancer through modulation of TLR4/NF-kappaB signaling by 6-shogaol. AAPS J 16: 246-257. DOI: 10.1208/s12248-013-9558-3. 